\section{Quick and easy to adapt into the cavity}

Whitening teeth containing conventional composites is problematic, leaving restorations that can stand out like a sore thumb. This could mean they need to be replaced.

Tokuyama's unique shadeless Omnichroma eliminates this problem. Because its patented spherical technology emits 'structural light', as the shade of the tooth lightens so the apparent shade of the Omnichroma restoration lightens to seamlessly match the new shade, whatever it is.

Tokuyama's shadeless Omnichroma combines patented 'structural colour' pearl technology with advanced resin expertise, so that just one shadeless Omnichroma and Omnichroma Blocker is all you need to replace all 16 Vita shades of any other composite system.

This means that there is no need to shade match ever again, and that just one pack saves the time and cost of on average 20 shade matches. Whilst its white opaque uncured appearance makes it clearly visible when packing and carving, it becomes invisible when cured and seamlessly matches the surrounding tooth shade whatever it is.

Quick and easy to adapt into the cavity it is extremely quick and easy to polish, again saving valuable time.

For more information about the complete Tokuyama range, including Omnichroma, contact your local Trycare Representative, call 01274885544 or visit www.trycare.co.uk/omnichroma.

\section{New showroom in Bracknell}

A-dec celebrated the recent opening of their Southern showroom in Bracknell by inviting press and industry contacts to a launch event.

The new showroom feels relaxing and stylish: a comfortable environment to explore the latest A-dec equipment. Conveniently situated between Heathrow and Reading, it means dentists in the south of England now have a near-by location in which to test their full range of equipment in addition to the Head office location in the Midlands.

Matt Turner, General Manager of A-dec UK, opened the event with a few words about the importance of visiting a showroom:

'Most dentists who purchase our equipment make this choice just once or twice in their entire career. A-dec equipment is built to last $20+$ years, so test driving the equipment in a showroom like this, really does ensure they get what they want with workflows that are efficient and effective.

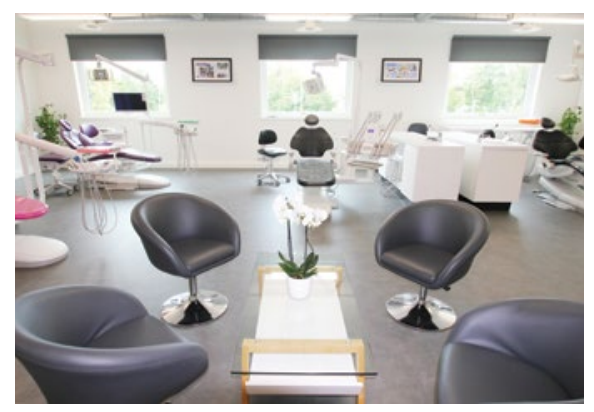

'Our Territory Managers are also trained and certified to deliver ergonomic assessments. This is critically important when making long-term choices as almost $66 \%$ of dental professionals are working in pain due to poor posture. Musculoskeletal disorders and debilitating back pain are one of the top reasons that dentists leave the profession or are forced into early retirement. We want to help our customers work pain free, so that they can have long and healthy careers and retire on their own terms.

To book a showroom appointment, call A-dec on 0800233285 or email info@a-dec. co.uk.

\section{Summer product savings}

All Meisinger products are now available for professionals to buy direct in the UK through their sister company, myplant.

As a special offer for readers of the British Dental Journal, myplant is offering a buy one get one free deal on some of the most popular products. These include any diamond instruments, tungsten carbide instruments, ceramic abrasives, flexible polishers and steel instruments!

This is an excellent opportunity to pick up your favourite instruments at a fantastic price or even discover something new.

To find out more, contact the team at myplant today.

Contact myplant on 08007797879 or email order@myplant-dental.com.

\title{
Gain confidence in implantology
}

Ucer Education offers a formal qualification in dental implantology to give clinicians complete confidence in their knowledge and skills.

The 12-month certification programme is presented by clinicians and education providers with extensive experience in the field, including renowned Specialist Oral Surgeon Professor Cemal Ucer.

Only the highest quality of products are used for training, including the innovative implant system from Neoss. Neoss implants

allow dental professionals to provide reliable and cost-effective treatments to their patients with excellent long-term results. They make complicated cases less complex, offering intelligent solutions that are intuitively simple to use.
If you're interested in gaining a formal

Eduqual Level 7 qualification, with on-going mentorship and support, consider the PG Cert

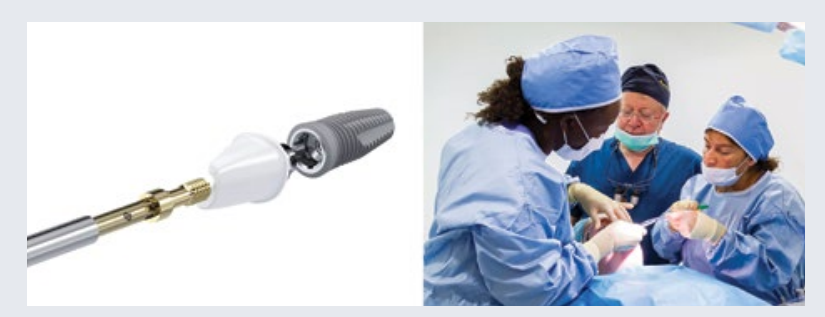

in Implant Dentistry from Ucer Education. For more information on the PG Cert in Implant Dentistry form Ucer Education, visit www.ucer.education or call 01612371842. 